\title{
Service expectations from high- and low-volume customers in the alcoholic beverage industry
}

\begin{abstract}
Authors:
Jacques Beukes ${ }^{1}$

J. J. (Hein) Prinsloo ${ }^{1}$

Theuns G. Pelser ${ }^{2}$

Affiliations:

${ }^{1}$ School of Management

Sciences, North-West

University, South Africa

${ }^{2}$ Graduate School of Business and Government Leadership,

North-West University,

South Africa

\section{Correspondence to:}

Theuns Pelser

Email:

theuns.pelser@nwu.ac.za

\section{Postal address:}

Private Bag X2046

Mmabatho 2735, South

Africa

Dates:

Received: 12 Feb. 2013

Accepted: 30 May 2013

Published: 12 Aug. 2013

How to cite this article: Beukes, J., Prinsloo, J.J. \& Pelser, T.G., 2013, 'Service expectations from high- and low-volume customers in the alcoholic beverage industry', Acta Commercii 13(1), Art. \#172, 8 pages. http://dx.doi. org/10.4102/ac.v13i1.172
\end{abstract}

\section{Copyright:}

(C) 2013. The Authors.

Licensee: AOSIS

OpenJournals. This work

is licensed under the

Creative Commons

Attribution License.
Read online:
Orientation: South Africa has a highly competitive alcoholic beverage market. All role players in this market place a huge emphasis on service delivery and customer service.

Research purpose: This research study investigated the relationship between the volume a customer buys from an alcoholic beverage supply company and what influence this volume has on their customer service expectations.

Motivation for the study: The main purpose of this study was to evaluate what influence the volume an organisation buys from alcoholic beverage suppliers has on their service quality expectations.

Research design, approach and method: A non-probability judgement sample method was used, with a sample size of 220 respondents. The questionnaire requested respondents (highand low-volume) to rank their customer service expectations and opinions with reference to Parasuraman's service delivery dimensions. Ranking was done using a five-point Likert scale.

Main findings: The findings of the study indicated that both the high- and low-volume customers felt that alcoholic beverage supply companies had to deliver on all five service delivery dimensions but failed to do so to full satisfaction.

Practical and managerial implications: It is recommended that the alcoholic beverage supply companies should address the problem areas identified in this study to avoid defection of customers.

Contribution and value add: This may assist alcoholic beverage supply companies to better understand the customers' demographic profiles. The study also revealed that the satisfaction level experienced by customers in both sections of the study (high- and low-demand), with a considerable gap between expectations and opinions within the empathy dimension.

\section{Introduction}

Many novel researchers (Cronin \& Taylor 1992, 1994; Grönroos 1984; Parasuraman, Zeithaml \& Berry 1985, 1988) have devoted considerable attention to the development and testing of models for the measurement of service quality in retail banks, long-distance telephone companies and credit-card companies. Previous empirical research has focused primarily on the measurement of service quality in hotels (Erto \& Vanacore 2002:165), on domestic airlines (Chang \& Yeh 2002:166), on tourists' judgements regarding service quality and on retailers' perceptions of the service levels at a tourist destination (Weiermair \& Fuchs 1999:1004). It is evident that previous empirical research has focused on service quality research in other sectors of the industry. Little attention has been given to investigating the influence that the volume or size of organisations that receive stock from numerous alcoholic beverage suppliers has on their customer service expectations and service quality expectations.

This study is based on the results from the service quality (SERVQUAL) questionnaire to compare what the effect of buying volume is on the customers of alcoholic beverage supply companies and their service quality expectations (Parasuraman et al. 1985, 1988). The SERVQUAL method mentioned above focuses on the customer's perception of service quality (Jiang, Klein \& Carr 2002:145; Kassim \& Bojei 2002:845). This plays an important role in the measurement of service quality at a service delivery company, as a result of the SERVQUAL five dimensions (tangibility, reliability, responsiveness, assurance and empathy). SERVQUAL also encompasses several previously-unexplored dimensions that have of late attracted research attention into other disciplines (Casadesus, Viadiu \& Saizarbitoria 2002; Jiang et al. 2002; Kang, James \& Alexandris 2002; Zhao, Bai \& Hui 2002).

Some of these previously-unexplored service dimensions or 'gaps' in the SERVQUAL method appear to be important and are worthy of investigation in the context of an alcoholic beverage 
supply company. These include: the gap between service specifications and service delivery; the discrepancy between customer expectations and their perceptions of the service delivered; the discrepancy between customer expectations and employees' perceptions; and customers' expectations versus management perceptions.

\section{Service quality and customer service}

Service quality has been of interest to marketing academics and managers since the early 1960s. Whilst products, process quality and total quality have emerged as being prime concerns in the manufacturing sector, service is acknowledged to be critical for all types of organisations (Ennew, Reed \& Binks 1993:59). Definitions of service quality, prior to 1985, focused on the complexity of customers in order to evaluate service quality, the development of perceptions of service quality expectations in relation to the actual service delivery and the involvement of quality assessment in the process of service delivery rather than the discrepancies that exist in the perception of expectations in the delivery of quality service to the customer (Parasuraman et al. 1985:42)

\section{Defining service quality}

Defining service quality is essentially difficult as the nature of services, particularly intangibility, complicates the meaning (Dhurup 2003:68). The result is that a generally agreedupon definition of what constitutes service quality does not exist (Grönroos 1984:36). As a result of the non-existence of a universally-accepted definition of service quality, some researchers have used basic theories in an effort to conceptualise service quality, namely, the Attribution Theory, the Customer Satisfaction Theory and the Interaction Theory (Boshoff 1990:143).

The Attribution Theory views service quality from a product-quality viewpoint by describing the attributes of the service delivery system. The theory assumes that the attribute of that which is thought constitutes service quality and can be manipulated by management. Gummeson (1988), for instance, identify four 'qualities' that establish apparent quality: design quality, production quality, delivery quality and relational quality. These qualities are regarded by the authors as being equally applicable to services.

The Customer Satisfaction Theory regards service quality as being a perception of quality, whereby a service only meets the desired criterion if the customer sees it as quality. In this theory, service quality is defined as being the distinction between expected service and actual service received (Marx 2005). This argument has been supported by Zeithaml, Bitner and Gremler (2009), who see service quality as being a dominant element in customers' evaluations. Delivering quality service means conforming to customer expectations on a consistent basis.

The Interaction Theory claims that service quality is shaped through personal interaction between the service firm workers and customers and that both parties benefit through the mutual satisfaction of desires. In addition, it is also evident that researchers (Weitz \& Wensley 2006; Zeithaml et al. 2009), in their attempt to define service quality, identified various dimensions or determinants of service quality.

Parasuraman et al. (1988:12-35) originally developed 10 dimensions and later reduced the number by correlation to five dimensions of service quality (SERVQUAL), namely, tangibility, reliability, responsiveness, assurance and empathy. These authors describe service quality in terms of perceived service quality as the degree and direction of difference between customers' perception and expectation. Service quality is therefore viewed as being a worldwide judgement of an attitude relating to the superiority of the service. Weitz and Wensley (2006:340) state that service quality comprises different elements, namely, physical quality, personnel, functional quality, corporate quality and interactive quality.

To obtain good service quality, a suitable mix of these elements must be found and balanced carefully. Grönroos (1984:37) also maintains that the most important part of a company, which customers see and perceive, is its services. According to him, therefore, the corporate image can be built mainly by the technical and the functional quality of its services and he also posits that, in some cases, the functional quality is more important than the technical quality dimension. Central to his dispute is the idea that the conceptualisation of service quality should be customer based and that customer perceptions of quality should thus be the main ingredient of a model of service quality. Placing greater emphasis on the functional quality dimensions is seen as being the main drawback of this model. Throughout the creation of the SERVQUAL model, it has given rise to some service quality gaps.

There are seven major gaps in the service quality concept (Shuttleworth 2006; Stromgren 2007; van Heerden 2010). According to the following description (Luk \& Layton 2002), the three important gaps, which are more associated with external customers, are Gaps 1, 5 and 6, since they have a direct relationship with customers:

- Gap 1: Customers' expectations versus management perceptions: a result of the lack of a marketing research orientation, insufficient upward communication and too many layers of management.

- Gap 5: The discrepancy between customer expectations and their perceptions of the service delivered, as a product of the influences exerted from the customer side and the shortfalls (gaps) on the part of the service provider. In this case, customer expectations are influenced by the extent of personal needs, word of mouth recommendation and past service experiences.

- Gap 6: The discrepancy between customer expectations and employees' perceptions: a result of the differences in the understanding of customer expectations by front-line service providers. 
As described previously, Parasuraman et al. (1988:12-35), through scale purification and successful elimination of substance, reduced the number of dimensions to five. This resulted in a 22-item scale. This study is based on the results from the SERVQUAL questionnaire comparing the effect of buying volume on customers of alcoholic beverage supply companies and their service quality expectations. The SERVQUAL method focuses on the customer's perception of service quality (Jiang et al. 2002; Kassim \& Bojei 2002:845). This plays an important role in the measurement of service quality at a service delivery company, in terms of the five dimensions noted before.

SERVQUAL further also encompasses several unexplored dimensions that have lately attracted research attention into other disciplines (Casadesus et al. 2002; Jiang et al. 2002; Kang et al. 2002; Zhao et al. 2002). Some of these unexplored service dimensions, or 'gaps', in the SERVQUAL method appear to be important and are worthy of investigation in the context of an alcoholic beverage supply company, as is discussed previously.

In today's highly-competitive FMCG (fast-moving consumer goods) market there is huge emphasis on service delivery and customer service, as a result of the fact that these two aspects can be seen as being the determining factors with regard to overall customer satisfaction and overall business performance. The market is divided into two main areas, namely, food and beverages. This article's emphasis is on the beverage side of the industry, which is divided into two sectors, namely, alcoholic beverages and non-alcoholic beverages. For the purposes of this study, the emphasis is on alcoholic beverages. The alcoholic beverage industry is categorised by means of the different categories of alcohol it produces (beer, cider, wine and spirits).

\section{Industry importance of service quality service delivery}

Providing dependable service has many benefits for a retail company. Companies that provide a reliable service have elevated levels of customer retention and benefits from positive word-of-mouth advertising (Dhurup 2003:82; Zeithaml et al. 2009). Providing superior quality service can boost a company's performance through increased market share. Reliable services can also lead to lesser costs (through having to re-perform the service less often) and improved productivity (resulting from higher employee morale and lower employee turnover). The following benefits, according to Dhurup (2003:83), are derived from service quality:

- Improved service.

- Higher profits.

- Increased retention and business from existing customers.

- Improved positive word-of-mouth communication.

- More opportunity to demand higher prices.

- Increased sales.

- Lower cost and higher productivity.

- Lower staff turnover.
- Higher morale and enthusiasm amongst staff.

- Reduced cost resulting from less redoing.

Findings from these studies by Dhurup (2003) and Zeithaml et al. (2009:546) reflect that companies offering superior service achieve higher than ordinary market share. These authors further argue that service quality and profitability affiliation take time to verify, part of the delay being due to the unfounded expectation that the connection is simple and straight. The cost of not delivering quality service is also high. If the retail company falls short of performing services at levels expected by a customer, the cost may go well beyond losing a single transaction. Customers who have received poor quality service will seldom tell the offending firm of their occurrence, but will instead spread word about the experience to friends and family. The value of service quality can be best appreciated by analysing its relationships with regard to profitability, price, market share and productivity.

\section{Problem statement and objectives}

South Africa has a highly-competitive alcoholic beverage market. All role players in this market place a huge emphasis on service delivery and customer service, because of the fact that these two aspects can be seen as being the determining factors in terms of overall customer satisfaction and business performance. The primary objective of this study is to investigate the relationship between the volume of alcoholic beverages purchased and customer service expectations. This objective is reached by means of the following secondary objectives:

- Ascertain whether customers perceive customer service differently based on their purchase quantity.

- Establish the perceptions customers have regarding service quality in relation to quantity purchased.

- Establish whether customer service is of equal importance for customers with different purchase quantities.

\section{Research method and design}

The target population comprised customers of alcoholic beverage supply companies situated in the North West province of South Africa. The sample frame selected for this study was obtained from a list of customers serviced by numerous alcoholic beverage supply companies based in this province. The North West province was chosen for this study because of definite disparities between high- and low-volume customers. The primary alcoholic beverage focus areas in the North West province are in Rustenburg, Mafikeng and Potchefstroom. A list of customers serviced by alcoholic beverage supply companies was acquired by using secondary data available on the companies' customer databases. The quantity of customers serviced by the different alcoholic beverage suppliers was established and the list was then divided into high-, medium- and low-volume customers. For the purposes of this study, the medium-volume customers were excluded as the research intended to focus on the two extremes (high- and low-volume customers). 
From the sample frame, a non-probability judgement sample method was chosen, which involves choosing sample units subjectively. The identified geographical areas (Rustenburg, Mafikeng and Potchefstroom) have 772, 738 and 690 customers respectively who receive deliveries from the alcoholic beverage supply companies. This added to 2200 customers (total population). Out of this total customer (population) base, 10\% was targeted within each area. This reflects a sufficient representation within each area. Customers (respondents) in these areas were then further divided into equal numbers of high- and low-volume customers. This sampling approach brought the quantity of targeted respondents to 220 , which is a $10 \%$ representation of the total population. The sample size selected for the study was thus 220 customers of the alcoholic beverage supply companies in the region. This was then divided equally between geographical areas and volume size.

The focus of this study was to obtain information regarding the influence that the volume of product that an organisation buys from alcoholic beverage suppliers has on their service quality expectations. This resulted in a descriptive research method being implemented. A cross-sectional survey design was used to reach the objectives of this study. Data was collected by means of a structured questionnaire, with 220 questionnaires that were distributed and returned (fifteen questionnaires were initially not completed in full and were returned to the respondents for completion). Items in the questionnaire were based on the SERVQUAL method adapted to fit this specific study. All questions were adapted to be applicable to the sample population of this study, which was collated into a book format with a cover page explaining the purpose, objectives and application of the study. Section A comprised the demographic details of the respondents and Section B consisted of a Likert scale based on the 22 items in the SERVQUAL-method questionnaire. Responses on this scale ranged from 1 (strongly agree) to 5 (strongly disagree). A pilot study was done on 1\% (22) of the total customer base to establish the reliability and validity of the questionnaire.

\section{Ethical considerations}

The following code of ethics was adhered to during the research process:

- Permission was obtained from the respondents in order to conduct interviews.

- Respondents were under no obligation to complete the questionnaire. Where a respondent refused to participate in the research, the respondent was thanked and the next qualifying respondent approached to participate in the research.

- Results of the research will be made available upon request to receivers and/or buyers of business organisations who participated in the study.

- Each respondent was informed of the purpose of the study.

- The questionnaire did not contain any questions detrimental to the self-interest of respondents.

- The researcher assured respondents that anonymity and confidentiality would be observed.
The researcher treated participants with fairness and equity during all stages of all stages of research.

\section{Trustworthiness}

The SERVQUAL model could be considered to possess content validity as well as the execution of the experimental assessment of the assessment of the convergent validity. The SERVQUAL model was assessed through an examination of whether the measured construct was associated empirically with measures of other conceptually-related variables. All of the above findings supported the model's validity.

\section{Reliability}

Reliability is concerned with the findings of the research study and relates to the credibility of the findings (Welman et al. 2012:145).

Malhotra (2007:285-286, 2010:318-319) and Welman (2012: 145-148) define the following several types of reliability:

- Test-retest reliability: an identical set of scale items is given to different groups at different times.

- Alternative forms reliability: two equivalent forms of the scale items are constructed. It is measured at two different times, with a different scale form being administered each time.

- Internal consistency reliability: the reliability of a summated scale where several items are summed to form a total score.

- Split-half reliability: items in a scale are divided into two halves and the resulting half scores are correlated.

The relationship between reliability and validity can be understood in terms of the true score model. If a measure is reliable it will also be perfectly valid and vice versa (Malhotra 2007:287). The opposite also applies in that if the measure is unreliable, it can't be perfectly valid.

For the purpose of this study, an internal consistency method was used by means of the coefficient alpha (Cronbach's alpha) reliability test. Coefficient alpha is a technique for judging internal consistency of a measurement instrument by averaging all the possible ways of splitting test items and then examining the degree of correlation. Coefficient alpha is a measure of squared correlation between experiential scores and factual scores. Variables derived from these test instruments are declared to be reliable only when they provide reliable and constant responses over frequent administration of the tests.

\section{Validity}

Malhotra (2007:286, 2010:320-321) and Smith and Albaum (2005) define validity as being the extent to which differences in observed scale scores reflect true differences amongst objects with regard to the characteristic being measured, rather than systematic or random error. This means that the conclusions and findings do indeed represent reality. This study made use of two main validities, namely face validity and validity check. 


\section{Face validity}

Content validity represents the degree to which the content of a measurement scale seems to tap all relevant aspects of an issue that can influence respondents' attitudes. One way to judge the validity of a scale is to request professionals or experts on the test topic to assess the scale (Malhotra 2007:286). Scales that pass this test are said to have content validity. This test of validity is highly one-sided, because the personal experiences and beliefs of the experts inevitably come into play.

Face validity is accessing by examining the measure with an 'eye' toward determining the domain that is sampled. It is therefore evident that face validation is a matter of subjective judgement. The collection of items in the initial stages should therefore be large enough so that after scale modification the measure still contains enough items to sample each of the variables' domains in an adequate manner.

\section{Validity check}

The questionnaire used in this study was adapted from a SERVQUAL model and questions adapted to the specific needs of this study. A validity check was thus very important in order to establish the feasibility of the questionnaire. After the face validity had been executed, the revised questionnaire was then administered to 22 respondents who formed part of the target population but were excluded from the final group of respondents. The respondents were also asked to give feedback regarding the overall questionnaire, for example if the questions were clear and easy to read and understand. The final questionnaire, with the relevant changes, was then administered to the actual target population.

\section{Results}

\section{Analysis and interpretation of findings}

For the first service quality dimension, namely Tangibility, the factor analysis returned determinant on the dimensions was 0.115 for tangibility expectations and 0.710 for tangibility opinions. This indicates that there was no severe multicollinearity between the dimensions items. The Kaiser-Meier-Olkin (KMO) result was 0.740 for tangibility expectations of the respondents and 0.784 for the tangibility opinions. This indicates that both of the sample sizes were seen as being acceptable. Both dimensions returned a $p$-value of $<0.05$. This shows a high enough correlation between the section items. All the communalities were $>0.3$ for each dimension section, indicating that the proportion variance of the item as explained by the factors is sufficient. Tangibility expectations returned a variance value of $69.746 \%$ as one factor and tangibility opinions, $76.343 \%$.

The factor analysis of the second dimension of service quality, namely Reliability expectations and opinions, returned a value $>0.3$, which shows that adequate variances of all items are explained by the factors. The factors explained $77.453 \%$ of the total variance in reliability expectations and $67.060 \%$ of the total variance in reliability opinions. The determinants for the respondents' expectations and opinions were 0.110 and 0.370 respectively, which is higher than the 0.00001 required to show no severe multicollinearity. The KMO measure was returned as 0.790 for reliability expectations and 0.752 for reliability opinions. This result shows that both expectations and opinions in this dimension illustrate sample adequacy. Both factors in the expectations and opinions section of the dimension returned a $p$-value of $<0.05$ on Bartlett's test.

The factor analysis of the third service quality dimension, namely Responsiveness expectations and opinions, returned a value higher than 0.3. The $p$-value returned for Bartlett's test on both sections was also $<0.05$. The KMO measure for responsiveness expectations was returned as 'good' (0.719) and opinions as 'medium' (0.5-0.7). The total variance of the two sections as explained by the factors returned a value of $64.17 \%$ (expectations) and $59.24 \%$ (opinions). Both factors returned a determinant of $>0.00001$.

The factor analysis of the fourth service quality dimension, namely Assurance expectations and opinions, returned a value $>0.3$.The $p$-value returned for Bartlett's test was also $<0.05$ on both factors' responses. The determinant figures returned on both sections of the dimension were $>00001$. The assurance expectations determinant result returned was 0.620 and assurance opinions, 0.080 . The KMO measure result returned was 0.776 on assurance expectations and 0.779 on assurance opinions, indicating sample adequacy for both. The total variance of both as explained by the factors returned a value of $64.280 \%$ for assurance expectations and $63.463 \%$ for assurance opinions.

The last dimension of service quality factor analysis, namely Empathy expectations and opinions, returned a value $>0.3$. The $p$-value reflected a high-enough correlation between the items, being $<0.05$ on both respondents' expectations and opinions of the empathy dimension. One factor explained $79.182 \%$ of the total variance on expectations and $70.124 \%$ of the total variance of opinions. The determinant returned 0.520 on empathy expectations and 0.144 on opinions. These returned results explain that there is no severe multicollinearity within this dimensions items. A KMO figure of 0.813 was returned for empathy expectations, which falls within the 'very good' category of the measure. A KMO figure of 0.777 was returned on the opinions customer questionnaire section for the empathy dimension, which is viewed as being 'good' for sample adequacy.

\section{Reliability}

All of the scales tested returned Cronbach alpha values of $>0.70$, which indicates good internal reliability (Pallant 2010:100). The results for the standard deviation were between 0.46 and 0.68 across the opinions and expectations for the five service quality dimensions. This indicates that there was only a small variation between the respondents' answers and that their opinions corresponded on most of the items. The mean values returned ranged from 1.72 to 1.88 on the five dimensions pertaining to the respondents' 
expectations. This result indicates that a relatively high number of the respondents agreed with the factor and that alcoholic beverage supply companies must deliver on these dimensions. The mean value returned on the opinions dimensions was in the range of 2.73-2.94. This indicates that most of the respondents had a neutral opinion regarding the actual service delivery from alcoholic beverage supply companies.

\section{High-volume dependant $\boldsymbol{t}$-test}

Table 1 illustrates the difference in high-volume respondents' opinions versus their expectations. Most of the high-volume respondents of alcoholic beverage supply companies felt that the companies should deliver on all five service quality dimensions but that, in their opinion, the companies did not necessarily deliver to the full satisfaction of the respondents. Most of the respondents didn't state whether they were getting satisfactory service or not, seen by the fact that their scoring fell closer to the neutral result than the 'agree' result based on the Likert scale. Practical significant differences between the means of high-volume respondents' expectations and opinions on all five dimensions can be observed. This reflects that most of the high-volume respondents felt that the alcoholic beverage supply companies must deliver on the respondents' expectations. The effect size clearly indicates that there is a difference between the expectations and opinions on all five dimensions for the high-volume respondents. The largest effect size was on the empathy ( $d=$ 2.20) and assurance $(d=1.99)$ dimensions. This indicates that most of the high-volume respondents expected good service delivery with regard to these dimensions but returned a neutral scoring on whether the alcoholic beverage supply companies actually deliver on these dimensions.

\section{Low-volume dependant $\boldsymbol{t}$-test}

Table 2 illustrates the difference in low-volume respondents' opinions versus their expectations. Most of the low-volume respondents of alcoholic beverage supply companies felt that the companies should deliver on all five service-quality dimensions but that, in their opinion, the companies did not deliver to the full satisfaction of these expectations. Most of the respondents didn't state whether they were getting satisfactory service or not, seen by the fact that their scoring fell closer to the neutral result than the 'agree' result based on the Likert scale. There are, however, large or practical significant differences within each service quality dimension for the low-volume respondents. There is a clear difference between the expectations and opinions of low-volume respondents.

The effect size displays that the low-volume respondents mostly expected good quality service delivery from alcoholic beverage supply companies across all the dimensions, but failed to indicate whether this was actually the case, with a neutral score being returned. The largest paired difference is also on the empathy dimension, with the result being $d=2.32$. This indicates that the respondents mostly felt that the alcoholic beverage supply companies should deliver on their expectations within this dimension but didn't indicate whether the companies delivered to their satisfaction or not. The second-largest difference was on the responsiveness dimension, $d=2.19$. This indicates again that the respondents mostly expected good service delivery on this dimension, but returned a neutral score with regard to their opinions of this dimension. This reveals that low-volume respondents mostly didn't indicate whether they were getting satisfactory service delivery or not.

\section{High- and low-volume respondents' expectations}

In Table 3, it emerges that in all the expectations dimensions it is clear that the respondents felt the same regarding what they expect from the alcoholic beverage supply companies with respect to delivery on the five service quality dimensions. This was primarily due to a mean value ranging between 1.65 (strongly agree to agree) and 2.05 (agree). This shows that the respondents mostly agreed that they expected the alcoholic beverage supply companies to deliver on the dimensions. Furthermore, it shows that all the respondents felt the same regarding their expectations that alcoholic beverage supply companies should deliver at a satisfactory level.

TABLE 1: High-volume respondent opinions versus expectations.

\begin{tabular}{lcccc}
\hline High-volume & Mean & Std. Deviation & Effect size & $p$-value \\
\hline $\begin{array}{l}\text { Tangibility } \\
\text { Expectations }\end{array}$ & 1.71 & 0.51 & 1.45 & $<0.001$ \\
Opinions & 2.76 & 0.73 & & \\
$\begin{array}{l}\text { Reliability } \\
\text { Expectations }\end{array}$ & 1.72 & 0.57 & 1.71 & $<0.001$ \\
Opinions & 2.80 & 0.63 & & \\
Responsiveness & & & & \\
Expectations & 1.68 & 0.51 & 1.86 & $<0.001$ \\
Opinions & 2.77 & 0.58 & & \\
Assurance & & & & \\
Expectations & 1.65 & 0.48 & 1.99 & $<0.001$ \\
Opinions & 2.80 & 0.58 & & \\
Empathy & & & & \\
Expectations & 1.65 & 0.53 & 2.2 & \\
Opinions & 3.00 & 0.62 & & \\
\hline
\end{tabular}

Source: Authors' own construction

TABLE 2: Low-volume respondents' opinions versus expectations.

\begin{tabular}{lcccc}
\hline Low-volume & Mean & Std. Deviation & Effect size & $p$-value \\
\hline $\begin{array}{l}\text { Tangibility } \\
\text { Expectations }\end{array}$ & 1.92 & 0.52 & 1.23 & $<0.001$ \\
$\begin{array}{l}\text { Opinions } \\
\text { Reliability }\end{array}$ & 2.70 & 0.64 & & \\
Expectations & & & & \\
Opinions & 2.05 & 0.64 & 0.99 & $<0.001$ \\
Responsiveness & 2.69 & 0.59 & & \\
Expectations & & & & \\
Opinions & 1.87 & 0.39 & 2.19 & $<0.001$ \\
Assurance & 2.80 & 0.43 & & \\
Expectations & & & & \\
Opinions & 1.81 & 0.5 & 1.93 & $<0.001$ \\
Empathy & 2.85 & 0.54 & & \\
Expectations & & & & \\
Opinions & 1.80 & 0.44 & 2.32 & \\
\hline
\end{tabular}

Source: Authors' own construction 


\section{High- and low-volume respondents' opinions}

Table 4 displays the independent $t$-test results for highand low-volume respondents' opinions. It is clear from the results that most of the dimensions had small or practically insignificant differences and both sections (high and low) agreed that they feel the same about the reality of the alcoholic beverage supply companies' service delivery on all five dimensions. This, as mentioned in previous sections, was a score of neutral, shown by the means on all the opinion dimensions being between 2.69 and 3.00 and the standard deviation being between 0.43 and 0.72 , showing agreement between the respondents' answers.

\section{Recommendations}

The majority of the customers of the beverage supply companies indicated that their expectations aren't being met. There were also gaps between the mean values of the expectations and opinions in the balance of the dimensions (tangibility, responsiveness, reliability, assurance and empathy). Alcoholic beverage supply companies need to evaluate which items within these dimensions are of importance to the customers and work on improving them, one by one.

TABLE 3: High and low-volume respondents' expectations.

\begin{tabular}{lcccc}
\hline Expectations & Mean & Std. Deviation & Effect size & $p$-value \\
\hline $\begin{array}{l}\text { Tangibility } \\
\text { High }\end{array}$ & 1.71 & 0.51 & 0.41 & 0.002 \\
Low & 1.92 & 0.52 & & \\
Reliability & & & & \\
High & 1.72 & 0.57 & 0.52 & 0.000 \\
Low & 2.05 & 0.64 & & \\
Responsiveness & & & & \\
High & 1.68 & 0.51 & 0.36 & 0.003 \\
Low & 1.87 & 0.39 & & \\
Assurance & & & & \\
High & 1.65 & 0.48 & 0.33 & 0.015 \\
Low & 1.81 & 0.50 & & \\
Empathy & & & & \\
High & 1.65 & 0.53 & 0.28 & 0.022 \\
Low & 1.80 & 0.44 & & \\
\hline
\end{tabular}

Source: Authors' own construction

TABLE 4: High and low-volume respondents' opinions.

\begin{tabular}{lcccc}
\hline Opinions & Mean & Std. Deviation & Effect size & $p$-value \\
\hline Tangibility & & & & \\
High & 2.76 & 0.72 & 0.08 & 0.516 \\
Low & 2.70 & 0.64 & & \\
Reliability & & & & \\
High & 2.80 & 0.63 & 0.17 & 0.187 \\
Low & 2.69 & 0.59 & & \\
Responsiveness & & & & \\
High & 2.77 & 0.58 & 0.06 & 0.599 \\
Low & 2.80 & 0.43 & & \\
Assurance & & & & \\
High & 2.80 & 0.58 & 0.08 & \\
Low & 2.85 & 0.54 & & 0.111 \\
Empathy & & & & \\
High & 3.00 & 0.62 & 0.19 & \\
Low & 2.89 & 0.47 & & \\
\hline
\end{tabular}

Source: Authors' own construction
It is recommended that the alcoholic beverage supply companies address the problem areas exposed in this study in order to avoid defection of customers and other repercussions associated with customer dissatisfaction. Furthermore, it is recommended that these companies strive for satisfactory levels of service delivery. It is suggested that employees at alcoholic beverage supply companies be made aware of the fact that their responsiveness, reliability, attitude, skills and knowledge are key and are important to the customers. It is also suggested that the alcoholic beverage companies provide customer-service training for all their call-centre agents and employees that work in the trade and face-to-face with the customer. An adapted SERVQUAL model could be used internally at alcoholic beverage supply companies to measure customer satisfaction on dimensions that they feel they are lacking in their service delivery to their customers. This adapted SERVQUAL model should be able to assist the alcoholic beverage supply companies in identifying gaps and in monitoring improvements made on these gaps. It is recommended that both managers and the alcoholic beverage supply companies themselves view all customers (both in the high- and low-volume sections) as being equally important. Finally, it is recommended that the same marketing, logistics and customer-service levers be implemented and used within both the low-volume and the high-volume sections of the industry.

\section{Summary and conclusions}

This study investigated the relationship between the volume a customer buys from an alcoholic beverage supply company and what influence this volume has on their customer service expectations. The study revealed that the satisfaction level experienced by customers in both the high-volume and lowvolume sections of the study demonstrated a considerable gap between expectations and opinions within the empathy dimension.

The findings of the study indicated that both the highand low-volume customers felt that alcoholic beverage supply companies had to deliver on all five service delivery dimensions but failed to do so to full satisfaction. There were also differences between the high- and low-volume customers' opinions and expectations. The results thus indicated that there are differences between high- and lowvolume customers' expectations and opinions regarding service delivery from alcoholic beverage supply companies.

The recommendations from the study, if used strategically and as a guideline, can improve an alcoholic beverage supply company's retention and profit growth. However, improved customer service can only be achieved if there is a paradigm shift away from the previous methods of interaction between companies and customers. Greater emphasis must also be placed on employee commitment and customer involvement. This requires challenging and engaging tasks, as well as good human relations with customers, coworkers and management. These factors play a very important role in satisfying customer needs and in delivering a service that 
is of a high quality. It is of the utmost importance that the service that is offered to the customer fulfils the highest levels of customer satisfaction

\section{Acknowledgments Competing interests}

Mr J. Beukes is currently an employee at South African Breweries, where the relevant empirical data regarding the population for the fieldwork was obtained, but this should present no conflict of interests.

\section{Authors' contributions}

J.B. (School of Management Sciences, North-West University) was the principal researcher, J.J.P. (School of Management Sciences, North-West University) was the project leader and T.G.P. (Graduate School of Business and Government Leadership, North-West University) wrote the manuscript.

\section{References}

Boshoff, H.C., 1990, 'Perceptions of service quality in three selected service industries', DCom thesis, Faculty of Economic and Management Sciences, University of Pretoria.

Casadesus, M., Viadiu, F.M. \& Saizarbitoria, I.H., 2002, 'Quality service of ISO 9000 consultants'. International Journal of Quality \& Reliability Management 19(8/9), 998-1013. http://dx.doi.org/10.1108/02656710210438096

Chang, Y.H. \& Yeh, C.H., 2002, 'A survey analysis of service quality for domestic airlines', European Journal of Operational Research 139(1), 166-177. http:// dx.doi.org/10.1016/S0377-2217(01)00148-5

Cronin Jr., J.J. \& Taylor, S.A., 1992, 'Measuring service quality: a re-examination and extension', Journal of Marketing 56(3), 55-68. http://dx.doi.org/10.2307/1252296

Cronin Jr., J.J. \& Taylor, S.A., 1994, 'SERVPERF versus SERVQUAL: reconciling performance-based and perceptions-minus-expectations measurement of service quality', Journal of Marketing 58(1), 125-131. http://dx.doi.org/10.2307/1252256

Dhurup, M., 2003, 'Consumer perceptions of supermarket service quality: Scale development, measurement and validation', PhD thesis, Faculty of Economic Sciences and Information Technology, North-West University.

Ennew, C.T., Reed, G.V. \& Binks, M.R., 1993, 'Importance-performance analysis and the measurement of service quality', European Journal of Marketing 27(2), 59-70. http://dx.doi.org/10.1108/03090569310026402

Erto, P. \& Vanacore, A., 2002, 'A probabilistic approach to measure hotel service quality', Total Quality Management \& Business Excellence 13(2), 165-174. http:// dx.doi.org/10.1080/09544120120102405
Grönroos, C., 1984, 'A service quality model and its marketing implications', European Journal of Marketing 18(4), 36-44. http://dx.doi.org/10.1108/ EUM0000000004784

Gummeson, E., 1988, Service quality and product quality combined', Review of Business 9(3), 14-19.

Jiang, J.J., Klein, G. \& Carr, C.L., 2002, 'Measuring information system service quality: SERVQUAL from the other side', MIS Quarterly 26(2), 145-166. http://dx.doi. org $/ 10.2307 / 4132324$

Kang, G.D., James, J. \& Alexandris, K., 2002, 'Measurement of internal service quality: application of the SERVQUAL battery to internal service quality', Managing Service Quality 12(5), 278-291. http://dx.doi.org/10.1108/09604520210442065

Kassim, N.M. \& Bojei, J., 2002, 'Service quality: gaps in the Malaysian telemarketing industry', Journal of Business Research 55(10), 845-852. http://dx.doi. org/10.1016/S0148-2963(00)00224-1

Luk, S.T.K. \& Layton, R., 2002, 'Perception gaps in customer expectations: Managers versus service providers and customers', The Service Industries Journal 22(2), 109-128. http://dx.doi.org/10.1080/714005073

Malhotra, N.K., 2007, Marketing research: An applied orientation, 5th edn., Prentice Hall, New Jersey

Malhotra, N.K., 2010, Marketing research: An applied orientation, 6th edn., Prentice Hall, New Jersey.

Marx, J.M.M., 2005, 'Customer service as an indication of service quality in South African supermarkets', MCom Dissertation, Faculty of Economic and Management Sciences, University of Pretoria.

Pallant, J., 2010, SPSS survival manual, 4th edn., McGraw-Hill, New York.

Parasuraman, A., Zeithaml, V.A. \& Berry, L.L., 1985, 'A conceptual model of service quality and its implications for future research', Journal of Marketing 49(4), 41-50.

Parasuraman, A., Zeithaml, V.A. \& Berry, L.L., 1988, 'SERVQUAL: a multiple-item scale for measuring consumer perceptions of service quality', Journal of Retailing 61(1), 12-40. http://dx.doi.org/10.2307/1251430

Shuttleworth, A.J., 2006, 'Assessing service quality in the South African advertising industry', MBA Dissertation, Faculty of Economic and Management Sciences, University of Pretoria.

Smith, S.M. \& Albaum, G.S., 2005, Fundamentals of marketing research, Sage Publications, California.

Stromgren, O., 2007, 'Analysing service quality: a study among Peruvian resort hotels', MSc Dissertation, Department of Business Administration, Technology and Social Sciences, Lulea University of Technology.

Van Heerden, J., 2010, 'Customer service at a private hospital in the North-West Province', MBA Dissertation, Faculty of Economic and Management Sciences, North-West University.

Weiermair, K. \& Fuchs, M., 1999, 'Measuring tourist judgment on service quality', Annals of Tourism Research 26(4), 1004-1021. http://dx.doi.org/10.1016/S01607383(99)00037-7

Weitz, B. \& Wensley, R., 2006, Handbook of Marketing, SAGE Publications Ltd, London.

Welman, C., Kruger, F. \& Mitchell, B., 2012, Research methodology, 5th edn., Oxford University Press, Cape Town.

Zeithaml, V.A, Bitner, M.J. \& Gremler, D.D., 2009, Service Marketing, 5th edn., McGraw Hill, New York.

Zhao, X. Bai, C. \& Hui, YV , 2002, 'An empirical assessment and application of the SERVQUAL in a Mainland Chinese department store', Total Quality of the SERVQUAL in a Mainland Chinese department store', Total Quality
Management \& Business Excellence 13(2), 241-254. http://dx.doi. org/10.1080/09544120120102478 